\title{
Risk Factors for Postpartum Depression Among Egyptian Women
}

\author{
Shaimaa Y. AbdElaziz ${ }^{1, *}$ MD; Hala W. Abdel Halim ${ }^{2}$ MD
}

\author{
*Corresponding Author: \\ Shaimaa Y. AbdElaziz \\ shosh1182@hotmail.com
}

Received for publication September 28,2020;Accepted January 3, 2021; Published online January 3, 2021.

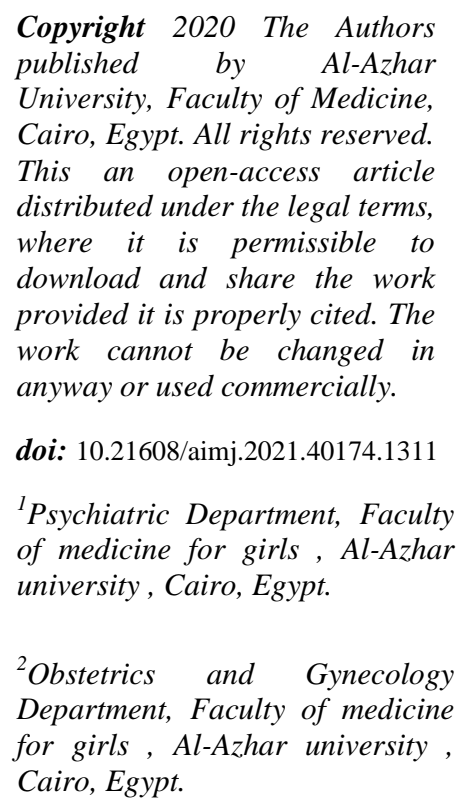

${ }^{2}$ Obstetrics and Gynecology Department, Faculty of medicine for girls , Al-Azhar university, Cairo, Egypt.

\section{ABSTRACT}

Background: Postpartum depression (PPD) is a severe health issue and is considered to have a negative effect on the wellbeing of mothers and on the physical and cognitive growth of children.Literatures on postpartum depression were confined in Egypt.The goals of this study are to establish the prevalence of postpartum depression as well as the underlying risk factors.

Objective: to assess the prevalence of postpartum depression and the risk factors that contributed to PPD.

Subjects and methods: From February 2019 to July2019 a crosssectional study was conducted involving 120 women whose youngestchild(ren) was less than 1 year old from obstetric outpatient clinic in Al-Zahraa University Hospital, Cairo, Egypt.The PPD symptoms were measured using an Arabic version of the Edinburgh Postnatal Depression Scale (EPDS).

Results: Postpartum depressionprevalence among 120 mothers (above the age of 18) was $27.5 \%$ in the first year after birth. Women who had suffered of domestic violence [OR: $6.4,95 \%$ CI: $2.5,15.3$ ], previously diagnosed with postpartum depression [OR: 5.5, 95\% CI: 1.6, 17.9], experienced stressful life events [OR: 3.6, 95\% CI: 1.4, 8.1] and difficulty in interaction with others when struggling [OR: $4.1,95 \% \mathrm{CI}$ : 1.7, 9.1] had greater odds of reporting PPD.

Conclusion: Postpartum depression (PPD) is a widespread, postnatal mental illness.Many factors may cause PPD to occur.Early detection of such factors can help in predicting PPD development.

Keywords: postpartum depression;Egyptian women; depression; domestic violence; postnatal depression.

Disclosure: The authors have no financial interest to declare in relation to the content of this article. The Article Processing Charge was paid for by the authors.

Authorship: All authors have a substantial contribution to the article.

\section{INTRODUCTION}

Postpartum depression (PPD) in the first year of childb irth is a common issue in maternal mental health Beck described it as the thief that steels motherhood. ${ }^{2}$

PPD prevalence was $13-40 \%^{3}$, as shown in a 2017 report published in the British Journal of Psychiatry. Women from developing countries reported higher PPD levels as opposed to women from developed countries ${ }^{4}$.

There were few studies in Arab countries on the prevalence of PPD. The prevalence of PPD in Lebanon is $21 \%,{ }^{5}$ United Arab Emirates (UAE) $22 \%,{ }^{6}$ Tunisia $19.2 \%,{ }^{7}$ Jordan $22 \%,{ }^{8}$ and $37.1 \%$ in Bahrain. ${ }^{9}$

Postpartum depression leads to increased maternal mortality by adversely impacting the needs of physical wellbeing and more specifically by suicide ${ }^{10}$.As a result, the development of children and future lives are seriously impaired by a defect in mother child relation ship,, a lack of breastfeeding and inadequate care ${ }^{11}$.
Domestic violence is a significant factor in the development of postpartum depression among women. ${ }^{12}$. Violence has serious implications for the psychological, mental, physical, and reproductive health of women. ${ }^{13,14}$.

Non-treatment or non-diagnosis of PPD may have a long term adverse effects ${ }^{15}$.

PPD is not well understood ${ }^{16}$, given its devastating impact in the low-income countries in particular.Consequently, an insight into and a strategy for implementing preventive approaches and early detection of the issue is essential.

\section{SUBJECTS AND METHODS}

This is a cross-sectional research that was completed at AL Zahraa University Hospital, Cairo-Egypt from February2019 to July2019.This study included all women whose youngest child is under the age of 1 and are over 18 years old. 120 Postpartum women 
were recruited from an obstetrical clinic at $\mathrm{AL}$ Zahraa Hospital and assessed at least twice by a psychiatrist and obstetrician: beginning at the first week after birth, then first, third, and twelfth month after delivery. Exclusion criteria were: (1) Associated neurological disease, eg, markedly affected cognitive function delirium or dementia;(2) Organic mental disorder, drug abuse and or mental retardation; (3) associated major medical problems; and (4) Severe Language or hearing difficulties. Consent was taken from all participants in this study and the importance of the study was explained and confidentiality of information was assured.This study and its protocol have been reviewed and approved by the Research Ethics Committee of faculty of medicine for girls. Cairo. Al-Azhar University (approval number 202005249, May 2020).

Methods : All women included in the study were subjected to the following:

- Sociodemographic characteristics, pregnancy and disease history (chronic diseases such as Hypertension, Diabetes Mellitus, Anemia and Cardiovascular Diseases) and Diseases during pregnancy ( Diabetes, preeclampsia and UTI) was taken.

- Family structure, Interpersonal skills and characteristics.

- Domestic violence, being the victim during the perinatal era if she mentioned any of the following encounters with a husband: being attacked or threatened with any weapon ; being kicked, or pushed ,or slapped, or beaten up; having something thrown at her; being physically paid to have sex and/or to perform any sexual relations when she has no desire.

- Edinburgh Postpartum Depression Scale (EPDS). The EPDS contains 10 items measured in a scale of $0-3$.The Arabic version of the EPDS ${ }^{17}$ was validated among Egyptian women and its psychometric accuracy is comparable to the original scale.Scores of 13 or more suggest significant depression.

Data analysis : Quantitative data were expressed as mean \pm standard deviation (SD). Qualitative data were expressed as frequency and percentage. All statistical analyses were performed using GraphPad
Prism software version 8 (GraphPad Software, Inc., La Jolla, CA, USA)

The following tests were done:

Chi-square (x2) test of significance was used in order to compare proportions between qualitative parameters.

The confidence interval was set to $95 \%$ and the margin of error accepted was set to $5 \%$. So, the pvalue was considered significant as the following:

Probability (P-value)

- P-value $<0.05$ was considered significant.

- P-value <0.001 was considered as highly significant.

- P-value >0.05 was considered insignificant.

\section{RESULTS}

A total of 120 postpartum women answered all the questions in detail. This table indicates that the EPDS cut-off level was $\geq 13$ and that postpartum depression prevalence was $27.5 \%$.

\begin{tabular}{|c|c|c|}
\hline Score of EPDS & N(120) & $\%$ \\
\hline$<13$ & 87 & $72.5 \%$ \\
\hline$\geq 13$ & 33 & $27.5 \%$ \\
\hline
\end{tabular}

Table 1: Scoring of EPDS

\section{Socio-Demographic Characteristics}

The respondents' mean age was 30 years, 6.7 SD.This table shows that there was a statistically significant difference between the depressive and non-depressive group as regard the work and education. The unemployed patients in the depressive group were $87.8 \%$ versus $68.9 \%$ in non-depressive group, and $48 \%$ were non-educated in the depressive group versus $16 \%$ in the non-depressive one. 


\begin{tabular}{|c|c|c|c|c|c|c|c|c|}
\hline $\begin{array}{l}\text { Socio- } \\
\text { demographic }\end{array}$ & $\begin{array}{l}\text { Total } \\
(\mathrm{n}=120)\end{array}$ & $\%$ & $\begin{array}{l}\text { Depression } \\
(n=33)\end{array}$ & $\%$ & $\begin{array}{l}\text { No } \\
\text { Depression } \\
(\mathrm{n}=87)\end{array}$ & $\%$ & $\mathrm{x} 2$ & p-value \\
\hline \multicolumn{9}{|l|}{ Residence } \\
\hline rural & 77 & $64.17 \%$ & 23 & $69.70 \%$ & 54 & $62.07 \%$ & \multirow[t]{2}{*}{0.6054} & \multirow[t]{2}{*}{0.4365} \\
\hline urban & 43 & $35.83 \%$ & 10 & $30.30 \%$ & 33 & $37.93 \%$ & & \\
\hline \multicolumn{9}{|l|}{ Work } \\
\hline employed & 31 & $25.83 \%$ & 4 & $12.12 \%$ & 27 & $31.03 \%$ & \multirow[t]{2}{*}{4.467} & \multirow[t]{2}{*}{$0.0346^{*}$} \\
\hline unemployed & 89 & $74.17 \%$ & 29 & $87.88 \%$ & 60 & $68.97 \%$ & & \\
\hline \multicolumn{9}{|l|}{ Education } \\
\hline primary & 1 & $0.83 \%$ & 0 & $0.00 \%$ & 1 & $1.15 \%$ & \multirow[t]{6}{*}{13.96} & \multirow[t]{6}{*}{$0.0158 *$} \\
\hline preparatory & 12 & $10.00 \%$ & 2 & $6.06 \%$ & 10 & $11.49 \%$ & & \\
\hline secondary & 3 & $2.50 \%$ & 1 & $3.03 \%$ & 2 & $2.30 \%$ & & \\
\hline faculty & 34 & $28.33 \%$ & 6 & $18.18 \%$ & 28 & $32.18 \%$ & & \\
\hline technical & 40 & $33.33 \%$ & 8 & $24.24 \%$ & 32 & $36.78 \%$ & & \\
\hline non educated & 30 & $25.00 \%$ & 16 & $48.48 \%$ & 14 & $16.09 \%$ & & \\
\hline \multicolumn{9}{|l|}{ Age } \\
\hline$<24$ & 27 & $22.50 \%$ & 6 & $18.18 \%$ & 21 & $24.14 \%$ & \multirow[t]{2}{*}{0.4867} & \multirow[t]{2}{*}{0.4854} \\
\hline$>24$ & 93 & $77.50 \%$ & 27 & $81.82 \%$ & 66 & $75.86 \%$ & & \\
\hline
\end{tabular}

x2: Chi-square test , $p$-value $>0.05$ NS; * $p$-value $<0.05 S$

Table2: Socio-demographic characteristics among women in postpartum period

Pregnancy and disease related factors :This table indicates statistically significant differences between the two groups as regard the presence of chronic diseases ( $39 \%$ in depressive vs $16 \%$ in non-depressive), diseases during pregnancy ( $54.5 \%$ in depressive vs $34.4 \%$ in non-depressive), planned pregnancy ( $42.4 \%$ in depressive vs $67.8 \%$ in non-depressive), parity ( $87.8 \%$ multiparous in depressive vs $68.9 \%$ in non-depressive) , previous psychiatric disorder ( positive in $21.2 \%$ in depressive vs $4.6 \%$ in non-depressive) and type of the newborn ( $60 \%$ female in depressive group vs $40.2 \%$ in non-depressive group).

\begin{tabular}{|l|l|l|l|l|l|l|l|l|}
\hline Pregnancy history & $\begin{array}{l}\text { Total } \\
(\mathbf{n = 1 2 0})\end{array}$ & \% & $\begin{array}{l}\text { Depressive } \\
(\mathbf{n = 3 3})\end{array}$ & $\mathbf{\%}$ & $\begin{array}{l}\text { Non } \\
\text { Depressive } \\
(\mathbf{n = 8 7})\end{array}$ & \% & x2 & P-value \\
\hline Chronic Diseases & & & & & & & & \\
\hline yes=1 & 27 & $22.50 \%$ & 13 & $39.39 \%$ & 14 & $16.09 \%$ & 7.45 & $0.0063 *$ \\
\hline no=0 & 93 & $77.50 \%$ & 20 & $60.61 \%$ & 73 & $83.91 \%$ & \\
\hline Newborn Type & & & & & & & & \\
\hline male=1 & 65 & $54.17 \%$ & 13 & $39.39 \%$ & 52 & $59.77 \%$ & 4.001 & $0.0455^{*}$ \\
\hline female=2 & 55 & $45.83 \%$ & 20 & $60.61 \%$ & 35 & $40.23 \%$ & & \\
\hline $\begin{array}{l}\text { Diseases during } \\
\text { pregnancy }\end{array}$ & & & & & & & & \\
\hline yes=1 & 48 & $40.00 \%$ & 18 & $54.55 \%$ & 30 & $34.48 \%$ & 4.013 & $0.0452^{*}$ \\
\hline
\end{tabular}




\begin{tabular}{|c|c|c|c|c|c|c|c|c|}
\hline no $=0$ & 72 & $60.00 \%$ & 15 & $45.45 \%$ & 57 & $65.52 \%$ & & \\
\hline \multicolumn{9}{|l|}{$\begin{array}{l}\text { past history of } \\
\text { abortion }\end{array}$} \\
\hline yes $=1$ & 23 & $19.17 \%$ & 10 & $30.30 \%$ & 13 & $14.94 \%$ & \multirow[t]{2}{*}{3.644} & \multirow[t]{2}{*}{0.0563} \\
\hline no $=0$ & 97 & $80.83 \%$ & 23 & $69.70 \%$ & 74 & $85.06 \%$ & & \\
\hline \multicolumn{9}{|c|}{ Breast-Feeding } \\
\hline yes $=1$ & 103 & $85.83 \%$ & 25 & $75.76 \%$ & 78 & $89.66 \%$ & \multirow[t]{2}{*}{3.8} & \multirow[t]{2}{*}{0.0512} \\
\hline no $=0$ & 17 & $14.17 \%$ & 8 & $24.24 \%$ & 9 & $10.34 \%$ & & \\
\hline \multicolumn{9}{|l|}{$\begin{array}{l}\text { Planned } \\
\text { Pregnancy }\end{array}$} \\
\hline yes $=1$ & 73 & $60.83 \%$ & 14 & $42.42 \%$ & 59 & $67.82 \%$ & \multirow[t]{2}{*}{6.474} & \multirow[t]{2}{*}{$0.0109 *$} \\
\hline no $=0$ & 47 & $39.17 \%$ & 19 & $57.58 \%$ & 28 & $32.18 \%$ & & \\
\hline \multicolumn{9}{|l|}{$\begin{array}{l}\text { Nullipara or } \\
\text { Multipara }\end{array}$} \\
\hline Nullipara=1 & 31 & $25.83 \%$ & 4 & $12.12 \%$ & 27 & $31.03 \%$ & \multirow[t]{2}{*}{4.467} & \multirow[t]{2}{*}{$0.0346^{*}$} \\
\hline Multipara=2 & 89 & $74.17 \%$ & 29 & $87.88 \%$ & 60 & $68.97 \%$ & & \\
\hline \multicolumn{9}{|l|}{$\begin{array}{l}\text { Previous } \\
\text { psychiatric } \\
\text { disorder }\end{array}$} \\
\hline yes $=1$ & 11 & $9.17 \%$ & 7 & $21.21 \%$ & 4 & $4.60 \%$ & \multirow[t]{2}{*}{7.932} & \multirow[t]{2}{*}{$0.0049 * *$} \\
\hline no=0 & 109 & $90.83 \%$ & 26 & $78.79 \%$ & 83 & $95.40 \%$ & & \\
\hline
\end{tabular}

Table 3: Pregnancy and psychiatric history among women in postpartum period

Family life, Interpersonal skills and Domestic violence

This table shows that $63 \%$ of patients in depressive group lived in extended family and $81 \%$ had arguments with the husband (unsatisfactory life). In addition, $87.8 \%$ of the women described their communication with others as limited than before and $57.5 \%$ had difficulty in interaction when struggling. Nearly $60.6 \%$ of the women in depressive group had stressful life events in the form of family member who died or had critical illnesses, injuries, and adverse conditions. Regarding Domestic violence $45.4 \%$ of the participants in depressive group were being a victim of domestic violence and all these data showed highly statistically significant difference when compared with the corresponding data in non- depressive group.

\begin{tabular}{|c|c|c|c|c|c|c|c|c|}
\hline $\begin{array}{l}\text { Family life, } \\
\text { interpersonal skills } \\
\text { and Domestic } \\
\text { violence }\end{array}$ & $\begin{array}{l}\text { Total } \\
(n=120)\end{array}$ & $\%$ & $\begin{array}{l}\text { Depression } \\
(\mathbf{n}=33)\end{array}$ & $\%$ & $\begin{array}{l}\text { No } \\
\text { depression } \\
(n=87)\end{array}$ & $\%$ & $\mathbf{x 2}$ & P-value \\
\hline \multicolumn{9}{|l|}{ Family Structure } \\
\hline Extended=1 & 56 & $46.67 \%$ & 21 & $63.64 \%$ & 35 & $40.23 \%$ & \multirow[t]{2}{*}{5.266} & \multirow[t]{2}{*}{$0.0217 *$} \\
\hline nuclear $=2$ & 64 & $53.33 \%$ & 12 & $36.36 \%$ & 52 & $59.77 \%$ & & \\
\hline \multicolumn{9}{|l|}{$\begin{array}{l}\text { Satisfaction about } \\
\text { family life }\end{array}$} \\
\hline feeling happy=1 & 68 & $56.67 \%$ & 6 & $18.18 \%$ & 62 & $71.26 \%$ & \multirow[t]{2}{*}{27.45} & \multirow[t]{2}{*}{$<0.0001 * * * *$} \\
\hline $\begin{array}{l}\text { having } \\
\text { arguments=2 }\end{array}$ & 52 & $43.33 \%$ & 27 & $81.82 \%$ & 25 & $28.74 \%$ & & \\
\hline \multicolumn{9}{|l|}{$\begin{array}{l}\text { Communicate and } \\
\text { interact with other }\end{array}$} \\
\hline as before $=1$ & 59 & $49.17 \%$ & 4 & $12.12 \%$ & 55 & $63.22 \%$ & \multirow[t]{2}{*}{24.99} & \multirow[t]{2}{*}{$<0.0001 * * * *$} \\
\hline $\begin{array}{l}\text { limited than } \\
\text { before }=2\end{array}$ & 61 & $50.83 \%$ & 29 & $87.88 \%$ & 32 & $36.78 \%$ & & \\
\hline \multicolumn{9}{|l|}{$\begin{array}{l}\text { Tell with others } \\
\text { when struggling }\end{array}$} \\
\hline yes $=1$ & 41 & $34.17 \%$ & 19 & $57.58 \%$ & 22 & $25.29 \%$ & \multirow[t]{2}{*}{11.09} & \multirow[t]{2}{*}{$0.0009 * * *$} \\
\hline no $=0$ & 79 & $65.83 \%$ & 14 & $42.42 \%$ & 65 & $74.71 \%$ & & \\
\hline $\begin{array}{l}\text { Having stressful life } \\
\text { events }\end{array}$ & & & & & & & & \\
\hline
\end{tabular}




\begin{tabular}{|c|c|c|c|c|c|c|c|c|}
\hline yes $=1$ & 46 & $38.33 \%$ & 20 & $60.61 \%$ & 26 & $29.89 \%$ & \multirow[t]{2}{*}{9.552} & \multirow[t]{2}{*}{$0.002 * *$} \\
\hline no $=0$ & 74 & $61.67 \%$ & 13 & $39.39 \%$ & 61 & $70.11 \%$ & & \\
\hline \multicolumn{9}{|c|}{ Domestic Violence } \\
\hline yes $=1$ & 25 & $20.83 \%$ & 15 & $45.45 \%$ & 10 & $11.49 \%$ & \multirow[t]{2}{*}{16.73} & \multirow[t]{2}{*}{$<0.0001 * * * *$} \\
\hline no $=0$ & 95 & $79.17 \%$ & 18 & $54.55 \%$ & 77 & $88.51 \%$ & & \\
\hline
\end{tabular}

Table 4: Family life, Interpersonal skills and Domestic violence among women in postpartum period

Factors associated with postpartum depression

The findings of the multivariate analysis showed in this table that domestic violence, prior history of mental health problems and extended type of family structure, stressful life events, interpersonal skill difficulties, chronic diseases and diseases during pregnancy have been positively correlated with postpartum depression symptoms.

Domestic violence has been shown to affect postnatal depression. Study participants suffering from domestic violence had six [OR: 6.4, $95 \%$ CI: 2.5, 15.3] times the odds of experiencing postpartum depression as compared to those with no history of domestic violence. Similarly, participants who hadtraumatic life events had around three [OR: 3.6, 95\% CI: 1.4, 8.1] times the risk of developing postpartum depression than their counterparts. Furthermore, the prior history of postpartum depression has also been shown to be associated to with the re-attack of postpartum depression. Respondents who had previously been diagnosed with depression had five [OR: 5.5, 95\% CI: 1.6, 17.9] times more likely to report symptoms of depression than those who had no past history. Difficulty in interaction with others when struggling had four [OR: 4.1, 95\% CI: 1.7, 9.1] times the risks of reporting postpartum depression in contrast to those who had no difficulties. Variables such as work, neonatal type, planned pregnancy, nullipara or multipara and family life satisfaction showed no correlation with postpartum depression symptoms.

\begin{tabular}{|l|c|c|c|}
\hline \multicolumn{1}{|c|}{ Variables } & \multirow{2}{*}{ Odd Ratio } & \multicolumn{2}{c|}{ 95\% C.I. } \\
\cline { 3 - 4 } & & Lower & Upper \\
\hline Work & 0.3065 & 0.1081 & 0.8872 \\
\hline Chronic Diseases & 3.389 & 1.429 & 8.031 \\
\hline Newborn Type & 0.4375 & 0.1878 & 1.022 \\
\hline Diseases during pregnancy & 2.28 & 1.037 & 5.121 \\
\hline Planned Pregnancy & 0.3497 & 0.1509 & 0.7962 \\
\hline Nullipara or Multipara & 0.3065 & 0.1081 & 0.8872 \\
\hline Previous psychiatric disorder & 5.587 & 1.55 & 17.83 \\
\hline Family Structure & 2.6 & 1.105 & 5.69 \\
\hline Satisfaction about family life & 0.08961 & 0.03368 & 0.2412 \\
\hline Communicate and interact with other & 0.08025 & 0.02885 & 0.2509 \\
\hline Tell with others when struggling & 4.01 & 1.78 & 9.095 \\
\hline Having stressful life events & 3.609 & 1.499 & 8.059 \\
\hline Domestic Violence & 6.417 & 2.583 & 15.37 \\
\hline
\end{tabular}

Table 5: Factors associated with postpartum depression in multivariate analysis

\section{DISCUSSION}

Postpartum depression is a major problem for maternal wellbeing in the first year after childbirth.The PPD prevalence in this study was 27.5 percent, as estimated by the EPDS with a cut-off point $\geq 13$.This corresponds with the prevalence range recorded in Asian countries, which revealed that PPD prevalence fluctuated from $3.5 \%$ to $63.3 \%{ }^{18}$ This was also consistent with the research conducted by Do et al. ${ }^{19}$ who studied 116 postpartum women in Hanoi and reported that the prevalence of PPD was $27.6 \%$ as assessed by EPDS with a cut-off point $\geq 12$.

Our analysis reported that the rate of PPD was larger than anticipated in Sohag $^{20}$ that PPD was $7.32 \%$ overall.The other sites in Egypt, however, reflected different prevalence, as the studies of Gharbia Governorate $^{21}$ and El-Minia ${ }^{22}$ reflected a higher prevalence of $20 \%$. The prevalence was also $17.9 \%$ in 
Mansoura study ${ }^{23}$.However, the prevalence was the largest in Assiut study ${ }^{24}$ being $51.7 \%$.

Our study results did not correlate with other research related to PPD's relationship with geographical (rural and urban) inequalities and other cultural issues. These variations can be influenced by the characteristics of the mothers (demographic pregnant experience and interpersonal characteristics) and the form of the test (sample, study time, cut-off point and method).

The current study observed that the mean age of PPD were $30.23 \pm 6.7$, our study did not find an association between age and PPD. This finding was consistent with Salah et al. ${ }^{23}$ and withCantilino et al. ${ }^{25}$ who did not find any difference in age between depressed and non-depressed Brazilian mothers.However, some findings have found that there is a significant relation between younger age and increased EPDS scores. ${ }^{26}$ Teenage mothers experience challenges during the post-partum era due to their inability to cope with emotional and financial pressures, as well as the burden of motherhood. ${ }^{27}$ Cultural influences and the social experiences of young mothers in various countries may be an explanation for this disparity.

In our study, women with chronic diseases and gestational diseases have a higher risk factor of PPD( twofold and threefold respectively) than women who have not.This was consistent with Abdollahi et al. ${ }^{28}$ reported that women with gestational diabetes had almost three times higher risk of postpartum depression when compared with women who did not.

Also, our study was Coherent with Kozhimannil et al.study that found a significant increase in depressive symptoms among women with gestational diabetes. ${ }^{29}$ Approximately $20-25$ per cent of diabetic patients are affected by depression, which is twice that of the general population. ${ }^{30}$ Although the associations and causes of disease factors (gestational diabetes, recurrent urinary tract infection, hypertension or hypotension, and hepatitis) are not clear regarding-PPD ${ }^{31,32}$. But it can be clarified that the pregnancy diseases continue to be a psychological load on mothers, with major effects on postpartum depression incidence.Additionally, among postpartum women in general, depression may be associated with lack of commitment to healthy lifestyle habits.

In this research, $21 \%$ of postpartum depression women had previous psychiatric problems prior to onset of PPD. Psychiatric symptoms prior to the development of PPD have been identified as a trigger of PPD by fivefold [OR: 5.5, 95\% CI: 1.6,17.9] and highly statistical significant according to $\mathrm{P}$ value. This is concordant with O'Haraet $\mathrm{al}^{33}$, who identified depressive symptoms as the best predictor of PPD during pregnancy.Deanand Kendell ${ }^{34}$ found that most PPD patients whose symptoms started during pregnancy had worsened symptoms within 2 weeks of delivery.However, there was no correlation between previous medical history and PPD in other studies $^{35,36}$.
As indicated in this study, domestic violence has been a critical indicator of postpartum depression [OR: 6.4, 95\% CI: 2.5, 15.3]. Despite the variations in criteria and definitions of abuse, studies from different parts of the world have shown a strong relationship between violence and risk of postnatal depression.In this review, aggression was usually physical and verbal (insulting) harassment.This was in line with Adamu and Adinew ${ }^{37}$ that domestic violence was found to have an impact on postnatal depression $\{$ AOR: 3.1, $95 \%$ CI: 1.6, 5.9].Furthermore, other Canadian studies38, Chili39, China40, and Pakistan41 indicated that participants with some kind of intimate partner abuse prior to or during pregnancy were at risk of postpartum mental health issues.In a longitudinal study from Iran, 42 women who were tested positive for postnatal depression were abused.

In our study, stressful life events is a strong predictor of developing PPD about three [OR: 3.6, 95\% CI: $1.4,8.1]$ times the odds. This is in agreement withRoumieh et al. ${ }^{43}$ who perceived that vulnerability to a lot of life stressors $(\mathrm{OR}=5.04 ; 95 \%[\mathrm{CI}]: 2.4-$ 10.5) had an impact factor on developing PPD. traumatic life events may be linked with depressive episodes that can trigger depressed emotions and increased feelings of hopelessness that causea depressive episode to occur after a stressful life event hasoccurred.As a result, depressed subjects were expected to experience more traumatic life experiences from the beginning of pregnancy and after childbirth compared to non-depressed subjects..

In this study, difficulty in interaction with others when struggling was a predictor of PPD [OR: 4.1, 95\% CI: $1.7,9.1$ ]. This was consistent with Do et al. ${ }^{19}$ who found that restricted communication / interaction with others when struggling would lead to the symptom of PPD [OR: 3.7, $95 \% \mathrm{CI}$ : $0.9,14.8] . S O$ women who communicate during the postpartum period and engage with others are at a lower risk of increasing postpartum depression.

\section{CONCLUSION}

Many factors had a contribution to the development of PPD, so this study made a valuable addition to knowledge about PPD prevalence and it related risk factors. At Psychiatrist and social worker should visit post-natal care unit to counsel mothers at risk of developing not only PPD but also other mental conditions as well. Screening for PPD should become standard by using EPDS postpartum for early detection and management.

\section{REFERENCES}

1. American Psychiatric Association. Diagnostic and statistical manual of mental disorders (DSM-5®). American Psychiatric Pub; 2013 May 22.

2. Beck CT. Postpartum depression: Stopping the thief that steals motherhood. AWHONN lifelines. 1999 Aug;3(4):41-4.

3. Dennis CL, Falah-Hassani K, Shiri R. Prevalence of antenatal and postnatal anxiety: systematic review 
and meta-analysis. The British Journal of Psychiatry. 2017 May;210(5):315-23.

4. Tronick E, Reck C. Infants of depressed mothers. Harvard review of psychiatry. 2009 Jan 1;17(2):14756.

5. Chaaya M, Campbell OM, El Kak F, Shaar D and Harb H, et al. Postpartum depression: prevalence and determinants in Lebanon. Archives of women's mental health. 2002 Oct 1;5(2):65-72.

6. Green K, Broome H, Mirabella J. Postnatal depression among mothers in the United Arab Emirates: sociocultural and physical factors. Psychology, health \& medicine. 2006 Nov 1;11(4):425-31.

7. Masmoudi J, Tabelsi S, Charfeddine F, Ayed BB and Guermazzi M, et al. Study of the prevalence of postpartum depression among 213 Tunisian parturients. Obstetrics \& Fertility Gynecology. 2008 Jul 1; 36 (7-8): 782-7.

8. Mohammad KI, Gamble J, Creedy DK. Prevalence and factors associated with the development of antenatal and postnatal depression among Jordanian women. Midwifery. 2011 Dec 1;27(6):e238-45.

9. Al Dallal FH, Grant IN. Postnatal depression among Bahraini women: prevalence of symptoms and psychosocial risk factors. EMHJ-Eastern Mediterranean Health Journal, 2012. 18 (5), 439-45.

10. Millennium Development Goal 5 - improving maternal health. Department of Mental Health and Substance Abuse World Health Organization $\mathrm{CH}-$ 1211 Geneva 27, Switzerland WHO, 2008;WHO/MSD/MER/08.01.

11. World Health Organization, Fact sheet on depression Available online at . http://www.who.int/ mental_health/ management/ depression/ definition/ en/. Accessed date November 28, 2015.

12. Ali NS, Ali BS, Azam IS. Postpartum anxiety and depression in peri-urban communities of Karachi, Pakistan: a quasi-experimental study. BMC public health. 2009 Dec 1;9(1):384.

13. Heise L. Violence against Women: The missing agenda. In Marjorie AK, Judith J, Jill G. editors. The health of women: A global perspective West view Press. 2012; 25-36.

14. United Nations: Division for the advancement of women, Department of Economic and Social Affairs. Secretary-General's In-Depth Study on Violence against Women. United Nations General Assembly, 61st Session: Advancement of Women, 2006. http://www.un.org/womenwatch/daw/vaw/ Ac cessed June 21, 2014.

15. Liu S, Yan Y, Gao X, Xiang S and Sha T, et al. Risk factors for postpartum depression among Chinese women: path model analysis. BMC pregnancy and childbirth. 2017 Dec;17(1):1-7.

16. Coast E, Leone T, Hirose A, Jones E. Poverty and postnatal depression: a systematic mapping of the evidence from low and lower middle income countries. Health \& place. 2012 .1;18(5):1188-97.
17. Ghubash R, Abou-Saleh MT, Daradkeh TK. The validity of the Arabic Edinburgh postnatal depression scale. Social psychiatry and psychiatric epidemiology. 1997 Nov 1;32(8):474-6.

18. Klainin P, Arthur DG. Postpartum depression in Asian cultures: a literature review. International journal of nursing studies. 2009 . 1;46(10):1355-73.

19. Do TK, Nguyen TT, Pham TT. Postpartum depression and risk factors among Vietnamese women.BioMed research international. 2018 Sep 18.

20. Salem MN, Thabet MN, Fouly H, Abbas AM. Factors affecting the occurrence of postpartum depression among puerperal women in Sohag city, Egypt.Proceedings in Obstetrics and Gynecology. 2017;7(1):1-0.

21. Mohamed NR, Ragab AZ, El Bahy MS, Zeina MA. Psychiatric disorders in the postpartum period.Menoufia Medical Journal. 2015 Apr 1;28(2):565.

22. Mohammed ES, Mosalem FA, Mahfouz EM, AbdElHameed MA. Predictors of postpartum depression among rural women in Minia, Egypt: an epidemiological study. Public Health. 2014 Sep $1 ; 128(9): 817-24$

23. Saleh ES, El-Bahei W, del El-Hadidy MA, Zayed A. Predictors of postpartum depression in a sample of Egyptian women. Neuropsychiatric disease and treatment. 2013;9:15.

24. Mohamed NA, Mahmoud GA, Said NA, Abdelhafez HA, Maklof AM. Postpartum depression: prevalence and predictors among women at El Eman's specialized hospital. J Am Sci. 2011;7(12):1-4.

25. Cantilino A, Zambaldi CF, Albuquerque TL, Paes JA and Montenegro AC, et al. Postpartum depression in Recife-Brazil: prevalence and association with biosocio-demographic factors. Jornal Brasileiro de Psiquiatria. 2010;59(1):1-9.

26. Chaudron LH, Klein MH, Remington P, Palta M and Allen $\mathrm{C}$, et al. Predictors, prodromes and incidence of postpartum depression. Journal of Psychosomatic Obstetrics \& Gynecology. 2001 Jan 1;22(2):103-12.

27. Sierra J. Risk Factors Related to Postpartum Depression in Low-Income Latina Mothers. Ann Arbor: ProQuest Information and Learning Company, 2008.

28. Abdollahi F, Zarghami M, Azhar MZ, Sazlina SG, Lye MS. Predictors and incidence of post-partum depression: A longitudinal cohort study. Journal of Obstetrics and Gynecology Research. 2014 Dec;40(12):2191-200.

29. Kozhimannil KB, Pereira MA, Harlow BL. Association between diabetes and perinatal depression among low-income mothers. Jama. 2009 Feb 25;301(8):842-7.

30. Anderson RJ, Freedland KE, Clouse RE, Lustman PJ. The prevalence of comorbid depression in adults with diabetes: a meta-analysis. Diabetes care. 2001 Jun 1;24(6):1069-78. 
31. Simpson W, Steiner M, Coote M, Frey BN. Relationship between inflammatory biomarkers and depressive symptoms during late pregnancy and the early postpartum period: a longitudinal study. Brazilian Journal of Psychiatry. 2016 Sep;38(3):1906.

32. Stagnaro-Green A, Abalovich M, Alexander E, Azizi $\mathrm{F}$ and Mestman J, et al. Guidelines of the American Thyroid Association for the diagnosis and management of thyroid disease during pregnancy and postpartum. Thyroid. 2011 Oct 1;21(10):1081-125.

33. O'Hara MW, Schlechte JA, Lewis DA, Wright EJ. Prospective study of postpartum blues: biologic and psychosocial factors. Archives of general psychiatry. 1991 Sep 1;48(9):801-6.

34. Dean C, Kendell RE. The symptomatology of puerperal illnesses.The British Journal of Psychiatry. 1981 Aug;139(2):128-33.

35. Hannah P, Adams D, Lee A, Glover V, Sandler M. Links between early post-partum mood and postnatal depression. The British Journal of Psychiatry. 1992 Jun 1;160(6):777-80.

36. Oyewumi LK, Odejide O, Kazarian SS. Psychiatric emergency services in a Canadian city: I. Prevalence and patterns of use. The Canadian Journal of Psychiatry. 1992 Mar;37(2):91-5.

37. Adamu AF, Adinew YM. Domestic violence as a risk factor for postpartum depression among Ethiopian women: Facility based study. Clinical practice and epidemiology in mental health: $C P$ \& $E M H$. 2018;14:109.
38. Desmarais SL, Pritchard A, Lowder EM, Janssen PA. Intimate partner abuse before and during pregnancy as risk factors for postpartum mental health problems.BMC pregnancy and childbirth. $2014 \mathrm{Dec}$ $1 ; 14(1): 132$

39. Quelopana AM. Violence against women and postpartum depression: the experience of Chilean women. Women \& health. 2012 Jul 1;52(5):437-53.

40. Zhang Y, Zou S, Cao Y, Zhang Y. Relationship between domestic violence and postnatal depression among pregnant Chinese women. International Journal of Gynecology \& Obstetrics. 2012 Jan 1;116(1):26-30.

41. Abbaszadeh A, Kermani FP, Safizadeh H, Nakhee N. Violence during pregnancy and postpartum depression. Pakistan Journal of Medical Sciences. 2011 Jan 1;27(1).177-181

42. Dolatian M, Hesami K, Shams J, Alavi MH.Relationship between Violence during Pregnancy and Postpartum Depression Iranian Red Crescent Medical Journal. 2010. 12(4): 377-383.

43. Roumieh M, Bashour H, Kharouf M, Chaikha S. Prevalence and risk factors for postpartum depression among women seen at Primary Health Care Centres in Damascus. BMC pregnancy and childbirth. 2019 Dec 1;19(1):519. 